\title{
ANALISA KLASIFIKASI DATA MINING PADA TINGKAT KEPUASAN PENGUNJUNG TAMAN HEWAN PEMATANG SIANTAR DENGAN ALGORITMA C4.5
}

\author{
Dinda Nabila Batubara ${ }^{1}$, Agus Perdana Windarto ${ }^{2}$ \\ 1,2 Program studi Sistem Informasi, STIKOM Tunas Bangsa \\ Jalan Jenderal Sudirman Blok A. No.1/2/3, Indonesia ${ }^{2}$ Afiliasi Penulis Dua
}

\begin{abstract}
Abstrak
Penelitian ini bertujuan untuk memberi rekomendasi kepuasan pengunjung taman hewan dengan menggunakan teknik datamining klasifikasi datamining C4.5. Sumber data diperoleh dari wawancara kepada pihak pengelola taman hewan kota Pematangsiantar dan pemberian kuisioner kepada pengujung secara random sebanyak 150 orang. Atribut yang digunakan sebagai parameter penilaian kepuasan pengunjung antara lain: Kemudahan akses menuju lokasi (C1), Sarana Prasarana (C2), Tempat parkir (C3), Keamanan (C4), Pelayanan Petugas (C5) dan Kebersihan (C6). Hasil pengolahan metode C4.5 dengan menggunakan bantuan software RapidMiner adalah atribut sarana prasarana (C2) dan pelayanan petugas (C5) menjadi atribut yang paling berpengaruh terhadap tingkat kepuasan pengunjung taman hewan. Dan data performance yang ditunjukkan terhadap kesesuaian metode $\mathrm{C} 4.5$ dengan kepuasan pengunjung taman hewan adalah $95 \%$
\end{abstract}

Kata Kunci: Datamining, Klasifikasi, Metode C4.5, Pengunjung, Kepuasan, Taman Hewan

\begin{abstract}
The purpose of the study is to provide recommendations for the satisfaction of visitors to the animal park using the C4.5 datamining classification data laminating technique. Data sources were obtained from interviews with the management of the Pematangsiantar City Animal Park and the giving of questionnaires to random visitors as many as 150 people. Attributes used as parameters for assessing visitor satisfaction include: Ease of access to locations (C1), Infrastructure Facilities (C2), Parking lots (C3), Security (C4), Service Officers (C5) and Cleanliness (C6). The results of processing the C4.5 method using the help of RapidMiner software are the attributes of infrastructure (C2) and service officers (C5) being the attributes that most influence the level of satisfaction of visitors to the park. And the performance data shown on the suitability of the C4.5 method with the satisfaction of visitors to the animal park is $95 \%$
\end{abstract}

Keywords: Datamining, Classification, C4.5 Method, Visitors, Satisfaction, Animal Park

\section{PENDAHULUAN}

Taman hewan merupakan salah satu objek wisata wisata yang saat ini banyak diminati masyarakat. Banyak hal yang harus diperhatikan dalam mengembangkan suatu objek wisata, yaitu dengan memberikan sesuatu yang sesuai dengan kebutuhan dan keinginan calon pengunjung. Antusiasme pengunjung terhadap suatu objek wisata berdampak pada tingginya jumlah kunjungan. Tingginya jumlah wisatawan mengharuskan pihak pengelola untuk memperhatikan kepuasan pengunjung. Kepuasan pengunjung merupakan suatu tingkatan dimana kebutuhan, keinginan dan harapan dari pelanggan dapat terpenuhi yang mengakibatkan terjadinya pembelian ulang atau kesetiaan yang berlanjut [1]. Banyak faktor yang mempengaruhi kepuasan pelanggan antara lain: faktor kebersihan. Banyak cabang ilmu komputer yang dapat menyelesaikan masalah secara kompleks. Mereka diantaranya adalah sistem pendukung keputusan [2]-[6], datamining [7]-[10], sistem pakar [11], jaringan saraf tiruan [12]-[15], algoritma genetika [16] dan lain-lain. Cabang ilmu tersebut semuanya masuk kedalam artificial inteligence (AI). Berdasarkan permasalahan yang dihadapi, peneliti menggunakan teknik datamining klasifikasi untuk menyelesaikan permasalah tingkat kepuasan pengunjung taman hewan di kota Pematangsiantar. Teknik datamining yang digunakana adalah algoritma klasifikasi C4.5. Penggunaan klasifikasi C4.5 berupa bentuk tingkatan yang berbeda mulai dari akar ke daun secara hirarki. Proses ini berlanjut hingga mencapai node yang tidak dapat dibagi lagi [17]. Beberapa penelitian terdahulu menggunakan metode C4.5 sebagai solusi dari permasalah yang diangkat seperti yang dilakukan [18]. Hasil penelitian menyimpulkan bahwa klasifikasi predikat keberhasilan mahasiswa di AMIK Tunas Bangsa dapat diterapkan. Atribut yang memiliki prioritas utama terhadap predikat keberhasilan mahasiswa adalah mahasiswa yang memilih sesi perkuliahan pada pagi hari dan didukung dengan nilai kehadiran > 50 maka mahasiswa tersebut mendapatkan predikat cumlade dibandingkan dengan mahasiswa yang berada di sesi perkuliahan siang dan malam. Berdasarkan alasan tersebut peneliti menggunakan metode C4.5 pada tingkat kepuasan pengunjung taman hewan yang bertujuan untuk melihat atribut yang paling berpengaruh pada kepuasan pengunjung di taman hewan. Dimana hasil dari penelitian memberikan manfaat bagi pihak taman hewan untuk menilai atribut yang paling berpengaruh dan paling tidak berpengaruh. Sehingga pihak taman hewan dapat meningkatkan kualitas pelayanan terhadap pengunjung berdasarkan hasil penelitian.

\section{TEORITIS}

\subsection{Data Mining}

Data mining disebut juga dengan Knowledge Discovery in Database (KDD) ataupun pattern recognition digunakan untuk memanfaatkan data dalam basis data dengan mengolahnya sehingga menghasilkan informasi baru yang 
berguna. Sedangkan istilah pattern recognition atau disebut pengenalan pola mempunyai tujuan pengetahuan yang akan digali dari dalam bongkahan data yang sedang dihadapi [19].

\subsection{Algoritma $\mathbf{C 4 . 5}$}

Algoritma C4.5 merupakan algoritma yang digunakan untuk membentuk pohon keputusan. Sedang pohon keputusan dapat diartikan suatu cara untuk memprediksi atau mengklarifikasi yang sangat kuat. Pohon keputusan dapat membagi kumpulan data yang besar menjadi himpunan-himpunan record yang lebih kecil dengan menerapkan serangkaian aturan keputusan. Rumus Algoritma C4.5 terbagi menjadi 2 rumus, yang pertama rumus untuk mencari nilai gain [20].

$\operatorname{Gaint}(S, A)=\operatorname{Entropy}(S)-\sum_{i=1}^{n} \frac{\left|S_{1}\right|}{|S|} * \operatorname{Entropy}(S i)$

Keterangan :

S : Himpunan Kasus

A : Atribut

n : Jumlah Partisi Atribut A

$\left|S_{1}\right|$ : Jumlah kasus pada partisi ke-i

$|S|$ : Jumlah Kasus dalam S

Dan rumus yang kedua adalah untuk mencari nilai entropy

$\operatorname{Entropy}(S)=\sum_{i=1}^{n}-p i * \log _{2} p i$

\subsection{Rapidminer}

RapidMiner merupakan suatu perangkat lunak yang bersifat terbuka (open source). RapidMiner merupakan sebuah solusi untuk melakukan analisis prediksi. RapidMiner menggunakan berbagai teknik deskriptif dan prediksi dalam memberikan wawasan kepada pengguna sehingga dapat membuat keputusan yang paling baik. RapidMiner memiliki kurang lebih 500 operator data mining, termasuk operator untuk input, output, data preprocessing dan visualisasi. RapidMiner merupakan software yang berdiri sendiri untuk analisis data dan sebagai mesin data mining yang dapat diitegrasikan pada produknya sendiri. RapidMiner ditulis dengan menggunakan bahasa java sehingga dapat bekerja di semua sistem operasi [20].

\section{HASIL DAN PEMBAHASAN}

Dengan menggunakan 6 kriteria anatar lain: Kemudahan akses menuju lokasi (C1), Sarana Prasarana (C2), Tempat parkir (C3), Keamanan (C4), Pelayanan Petugas (C5) dan Kebersihan (C6) peneliti memperoleh data dengan membagikan angket atau kuisioner kepada 150 responden secara random kepada pengunjung Taman Hewan Pematangsiantar. Data diakumulasi dengan menggunakan bantuan software microsoft excel.

Tabel 1. Data Akumulasi

\begin{tabular}{|c|c|c|c|c|c|c|}
\hline $\begin{array}{c}\text { Kemudahan Akses Menuju } \\
\text { lokasi }\end{array}$ & Sarana Prasana & $\begin{array}{l}\text { Tempat } \\
\text { Parkir }\end{array}$ & Keamanan & $\begin{array}{l}\text { Pelayanan } \\
\text { Petugas }\end{array}$ & Kebersihan & Keputusan \\
\hline Mudah diakses oleh kendaraan & Sangat lengkap & Luas & Aman & Ramah & Bersih & Puas \\
\hline Mudah diakses oleh kendaraan & Kurang Lengkap & Sempit & Aman & Ramah & Bersih & Puas \\
\hline Mudah diakses oleh kendaraan & Kurang Lengkap & Luas & Tidak Aman & Cuek & Bersih & Puas \\
\hline Susah diakses oleh kendaraan & Sangat lengkap & Sempit & Tidak Aman & Sombong & Bersih & Tidak Puas \\
\hline Mudah diakses oleh kendaraan & Sangat lengkap & Sempit & Aman & Sombong & Bersih & Tidak Puas \\
\hline Susah diakses oleh kendaraan & Tidak lengkap & Luas & Tidak Aman & Ramah & Kotor & Tidak Puas \\
\hline Susah diakses oleh kendaraan & Sangat lengkap & Luas & Aman & Sombong & Bersih & Puas \\
\hline Mudah diakses oleh kendaraan & Tidak lengkap & Luas & Aman & Ramah & Bersih & Puas \\
\hline Mudah diakses oleh kendaraan & Sangat lengkap & Sempit & Aman & Sombong & Bersih & Puas \\
\hline Susah diakses oleh kendaraan & Tidak lengkap & Luas & Aman & Ramah & Bersih & Puas \\
\hline Mudah diakses oleh kendaraan & Sangat lengkap & Luas & Tidak Aman & Cuek & Kotor & Tidak Puas \\
\hline Mudah diakses oleh kendaraan & Tidak lengkap & Sempit & Aman & Cuek & Bersih & Puas \\
\hline Mudah diakses oleh kendaraan & Sangat lengkap & Sempit & Aman & Ramah & Bersih & Puas \\
\hline Susah diakses oleh kendaraan & Sangat lengkap & Luas & Tidak Aman & Sombong & Bersih & Tidak Puas \\
\hline Mudah diakses oleh kendaraan & Tidak lengkap & Sempit & Aman & Cuek & Kotor & Tidak Puas \\
\hline Mudah diakses oleh kendaraan & Sangat lengkap & Luas & Tidak Aman & Cuek & Bersih & Puas \\
\hline Mudah diakses oleh kendaraan & Sangat lengkap & Sempit & Aman & Ramah & Bersih & Puas \\
\hline Susah diakses oleh kendaraan & Tidak lengkap & Luas & Tidak Aman & Ramah & Bersih & Tidak Puas \\
\hline Mudah diakses oleh kendaraan & Sangat lengkap & Sempit & Aman & Cuek & Kotor & Tidak Puas \\
\hline Mudah diakses oleh kendaraan & Tidak lengkap & Sempit & Aman & Ramah & Bersih & Puas \\
\hline
\end{tabular}

Pada tahap selanjutnya data akan di proses menggunakan bantuan Tools RapidMiner maka data akan terlihat pohon keputusan, dan rulenya. Setelah dilakukan perhitungan metode algoritma C4.5 pada RapidMiner, maka terbentuk pohon keputusan seperti gambar di bawah ini : 


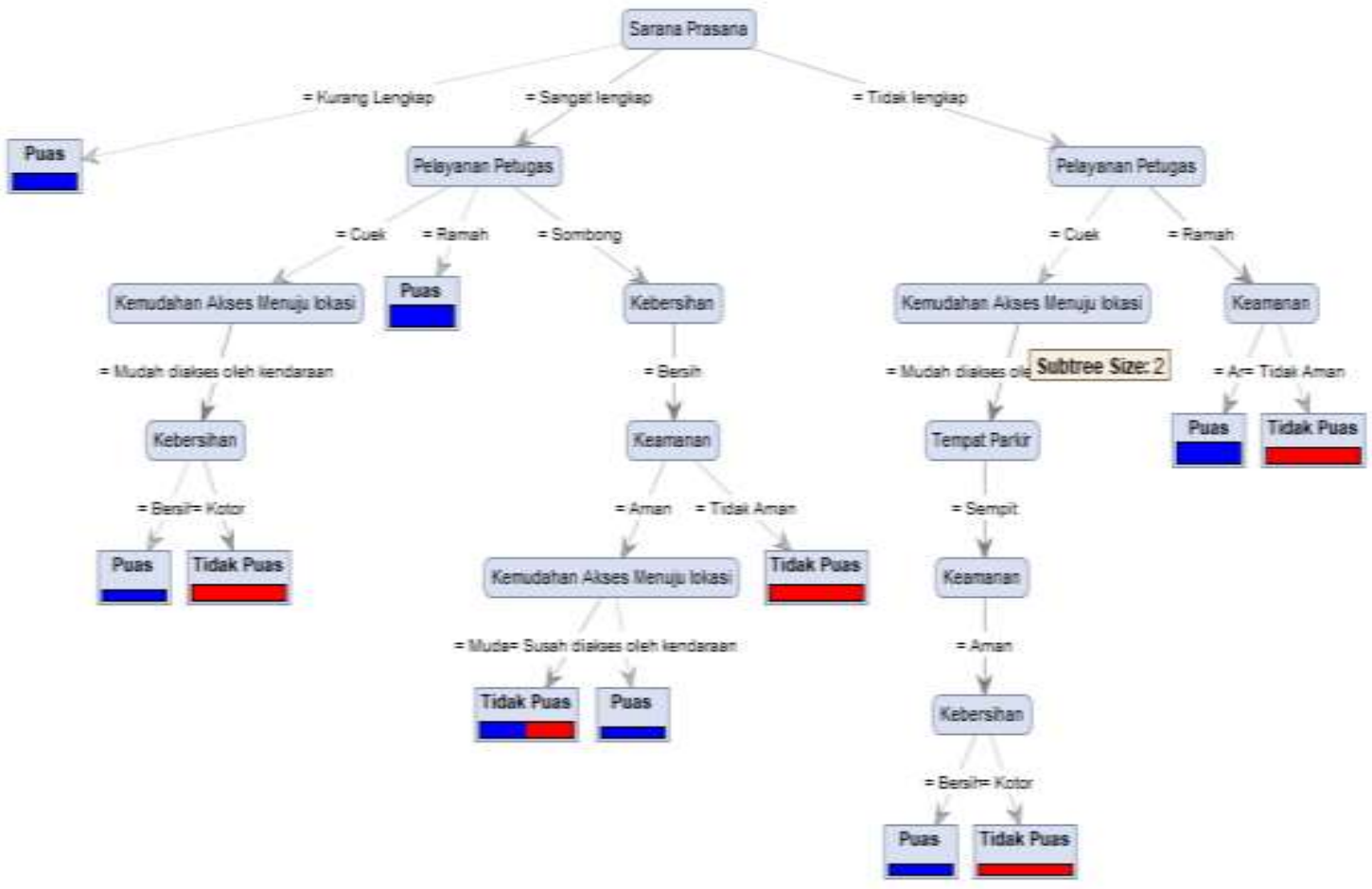

Gambar 1. Decision Tree

Pohon Keputusan diatas menghasilkan rule yang akan diimplementasikan pada program. Rule yang dihasilkan adalah sebagai berikut:

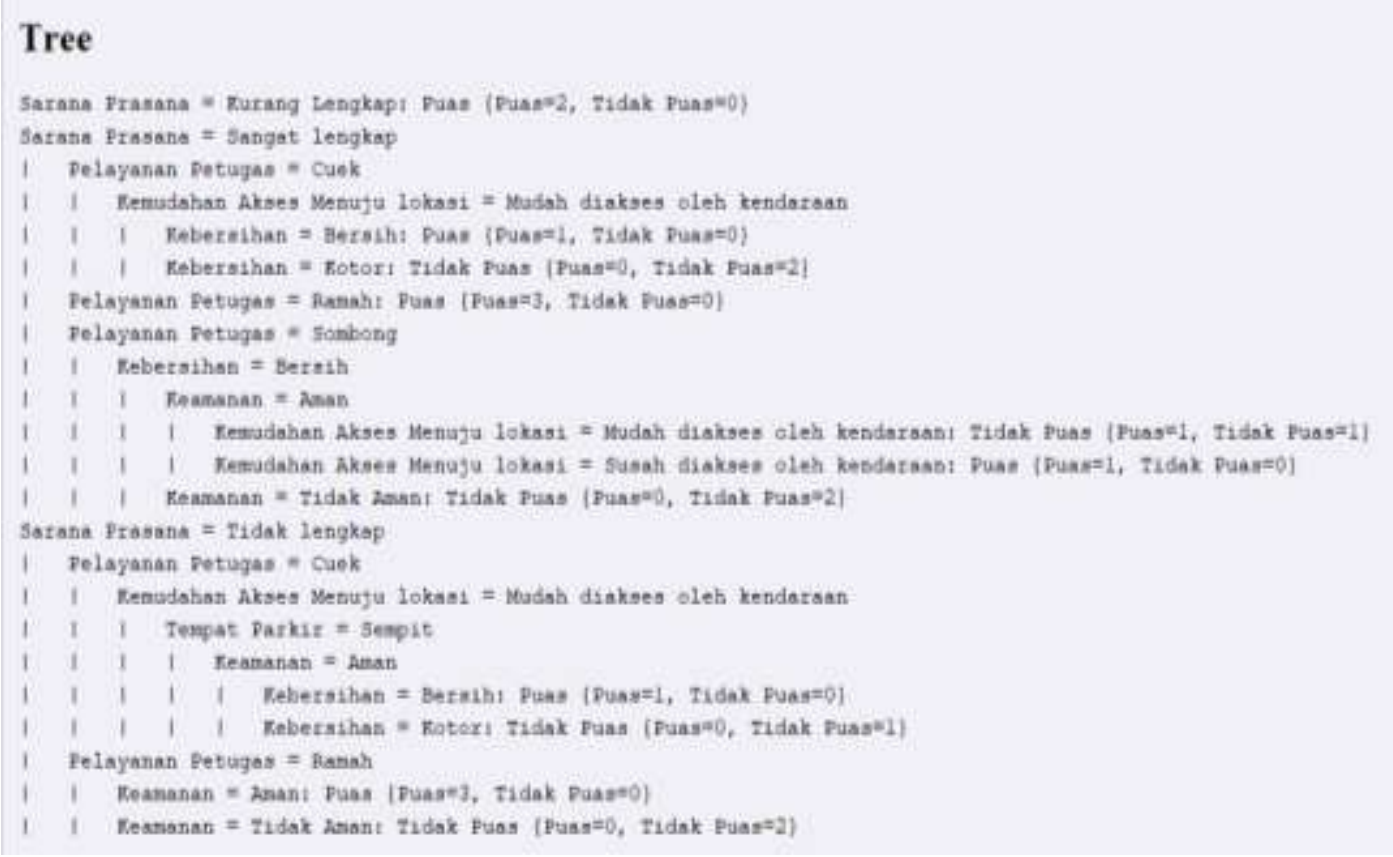

Gambar 2. Rule

Berdasarkan gambar 2 dapat dijelaskan bahwa dari 6 atribut penilaian terhadap kepuasan pengunjung taman hewan kota Pematangsiantar (Kemudahan akses menuju lokasi (C1), Sarana Prasarana (C2), Tempat parkir (C3), Keamanan (C4), Pelayanan Petugas (C5), Kebersihan (C6)), diperoleh atribut sarana prasarana (C2) dan pelayanan petugas (C5) menjadi atribut yang paling berpengaruh terhadap tingkat kepuasan pengunjung taman hewan. Dalam hal ini juga peneliti menguji kebenaran data yang digunakan, apakah metode klasifikasi C4.5 dapat diterapkan pada kepuasan pengunjung dengan bantuan software RapidMiner. Hasil perhitungan software RapidMiner menunjukkan akurasi menggunakan tools performance adalah $95 \%$. Hal ini membuktikan bahwa metode C4.5 dapat digunakan untuk menilai kepuasan pengunjung. 


\section{PerformanceVector}

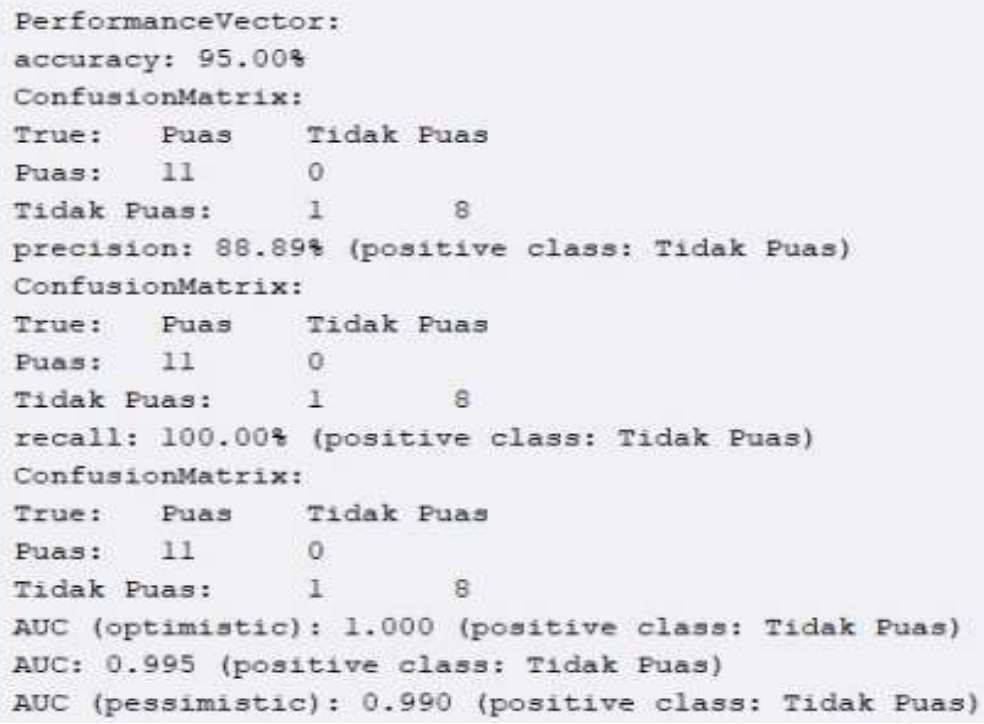

Gambar 3. Performance

\section{KESIMPULAN}

Berdasarkan hasil penelitian dapat disimpulkan bahwa Algoritma C4.5 dapat diterapkan dalam menentukan tingkat kepuasan pelanggan Taman Hewan Pematangsiantar. Dari 6 (enam) atribut antara lain: Kemudahan akses menuju lokasi (C1), Sarana Prasarana (C2), Tempat parkir (C3), Keamanan (C4), Pelayanan Petugas (C5) dan Kebersihan (C6) diperoleh atribut sarana prasarana (C2) dan pelayanan petugas (C5) menjadi atribut yang paling berpengaruh terhadap tingkat kepuasan pengunjung taman hewan. Dalam hal ini juga peneliti menguji kebenaran data yang digunakan, apakah metode klasifikasi C4.5 dapat diterapkan pada kepuasan pengunjung dengan bantuan software RapidMiner. Hasil perhitungan software RapidMiner menunjukkan akurasi menggunakan tools performance adalah $95 \%$.

\section{REFERENCES}

[1] Zelmiati, Waryono, and Youmil, "PENGARUH KUALITAS PELAYANAN TERHADAP KEPUASAN PENGUNJUNG DI OBJEK WISATA MINANG FANTASI KOTA PADANG PANJANG,” 2017.

[2] S. M. Dewi and A. P. Windarto, "Analisis Metode Electre Pada Pemilihan Usaha Kecil Home Industry Yang Tepat Bagi Mahasiswa," Sist. J. Sist. Inf., vol. 8, no. 3, pp. 377-385, 2019.

[3] D. R. S. P, A. A. Muin, and M. Amin, "PEMILIHAN FACIAL WASH UNTUK KULIT WAJAH BERMINYAK DENGAN METODE PROMETHEE II," CESS (Journal Comput. Eng. Syst. Sci., vol. 4, no. 2, pp. 222-229, 2019.

[4] C. Astria, A. P. Windarto, and Z. Musiafa, "PEMILIHAN PRODUK SAMPO SESUAI JENIS KULIT KEPALA DENGAN METODE PROMETHEE II,” CESS (Journal Comput. Eng. Syst. Sci., vol. 4, no. 2, pp. 178-185, 2019.

[5] D. N. Batubara, A. P. Windarto, and M. R. Raharjo, "PENERAPAN PROMETHEE II PADA PEMILIHAN PRODUK CONDITIONER SEBAGAI UPAYA PENINGKATAN MINAT BELI KONSUMEN,” CESS (Journal Comput. Eng. Syst. Sci., vol. 4, no. 2, pp. 191-197, 2019

[6] D. N. Batubara, D. R. S. P, and A. P. Windarto, "Penerapan Metode PROMETHEE II Pada Pemilihan Situs Travel Berdasarkan Konsumen," J. SISFOKOM, vol. 8, no. 1, pp. 46-52, 2019.

[7] A. P. Windarto, "Penerapan Datamining Pada Ekspor Buah-Buahan Menurut Negara Tujuan Menggunakan K-Means Clustering Method," Techno.Com, vol. 16, no. 4, pp. 348-357, 2017.

[8] M. G. Sadewo et al., "PENERAPAN ALGORITMA CLUSTERING DALAM MENGELOMPOKKAN BANYAKNYA DESA / KELURAHAN MENURUT UPAYA ANTISIPASI / MITIGASI BENCANA ALAM MENURUT PROVINSI DENGAN K-MEANS," vol. 2, pp. 311-319, 2018.

[9] H. Siahaan, H. Mawengkang, S. Efendi, A. Wanto, and A. P. Windarto, "Application of Classification Method C4 . 5 on Selection of Exemplary Teachers," in IOP Conference Series, 2018, pp. 1-6.

[10] Sudirman, A. P. Windarto, and A. Wanto, "Data mining tools | rapidminer: K-means method on clustering of rice crops by province as efforts to stabilize food crops in Indonesia," IOP Conf. Ser. Mater. Sci. Eng., vol. 420, p. 12089, 2018.

[11] S. Azhar, H. Latipa, S. Leni, and N. Zulita, "Sistem Pakar Penyakit Ginjal Pada Manusia Menggunakan Metode Forward Chaining," J. Media Infotama, vol. 10, no. 1, pp. 16-26, 2014.

[12] T. Budiharjo, Soemartono, T., Windarto, A.P., Herawan, "Predicting tuition fee payment problem using backpropagation neural network model," Int. J. Adv. Sci. Technol., 2018.

[13] T. Budiharjo, Soemartono, T., Windarto, A.P., Herawan, "Predicting school participation in indonesia using back-propagation algorithm model," Int. J. Control Autom., 2018.

[14] A. P. Windarto, M. R. Lubis, and Solikhun, "MODEL ARSITEKTUR NEURAL NETWORK DENGAN BACKPROPOGATION PADA PREDIKSI TOTAL LABA RUGI KOMPREHENSIF BANK UMUM KONVENSIONAL,” Kumpul. J. Ilmu Komput., vol. 5, no. 2, pp. 147158,2018

[15] A. P. Windarto, M. R. Lubis, and Solikhun, "IMPLEMENTASI JST PADA PREDIKSI TOTAL LABA RUGI KOMPREHENSIF BANK 
UMUM KONVENSIONAL DENGAN BACKPROPAGATION,” J. Teknol. Inf. dan Ilmu Komput., vol. 5, no. 4, pp. 411-418, 2018

[16] Sumijan, A. P. Windarto, A. Muhammad, and Budiharjo, "Implementation of Neural Networks in Predicting the Understanding Level of Students Subject," Int. J. Softw. Eng. Its Appl., vol. 10, no. 10, pp. 189-204, 2016.

[17] D. W. T. Putra, "Algoritma C4.5 untuk Menentukan Tingkat Kelayakan Motor Bekas yang Akan Dijual," J. TEKNOIF, vol. 4, no. 1, pp. 1622, 2016.

[18] Y. S. Luvia, A. P. Windarto, S. Solikhun, and D. Hartama, "Penerapan Algoritma C4.5 Untuk Klasifikasi Predikat Keberhasilan Mahasiswa Di Amik Tunas Bangsa," Jurasik (Jurnal Ris. Sist. Inf. dan Tek. Inform., vol. 1, no. 1, pp. 75-79, 2017.

[19] M. G. Sadewo, A. Eriza, A. P. Windarto, and D. Hartama, "Algoritma K-Means Dalam Mengelompokkan Desa / Kelurahan Menurut Keberadaan Keluarga Pengguna Listrik dan Sumber Penerangan Jalan Utama Berdasarkan Provinsi,” pp. 754-761, 2019.

[20] G. Syahputra, "Penerapan Algoritma C4 . 5 Dalam Analisa Kelayakan Penerima Bonus Tahunan Pegawai ( Studi Kasus : PT . Multi Pratama Nauli Medan )," J. Mantik Penusa, vol. 16, no. 2, 2014. 